TITLE:

\title{
Titanium nitride prepared by plasma-based titanium-ion implantation
}

\section{$\operatorname{AUTHOR}(S):$}

Yukimura, K; Sano, M; Maruyama, T; Kurooka, S; Suzuki, Y; Chayahara, A; Kinomura, A; Horino, Y

\section{CITATION:}

Yukimura, K ...[et al]. Titanium nitride prepared by plasma-based titanium-ion implantation. JOURNAL OF VACUUM SCIENCE \& TECHNOLOGY B 1999, 17(2): 840-844

\section{ISSUE DATE:}

1999

URL:

http://hdl.handle.net/2433/43542

RIGHT:

Copyright 1999 American Vacuum Society 


\title{
Titanium nitride prepared by plasma-based titanium-ion implantation
}

\author{
Ken Yukimura ${ }^{\text {a) }}$ and Masanori Sano \\ Department of Electrical Engineering, Faculty of Engineering, Doshisha University, 1-3, \\ Tatara-Miyakodani, Kyotanabe, Kyoto 610-0321, Japan \\ Toshiro Maruyama ${ }^{\text {b) }}$ \\ Department of Chemical Engineering, Faculty of Engineering, Kyoto University, Yoshida-Honmachi, \\ Kyoto 606-8501, Japan \\ Shunji Kurooka and Yasuo Suzuki \\ Ion Engineering Research Institute Corporation (IERIC), 2-8-1, Yamate, Tsuda, Hirakata, Osaka 573-0128, \\ Japan
}

Akiyoshi Chayahara, Atsushi Kinomura, and Yuji Horino ${ }^{\mathrm{c})}$

Osaka National Research Institute, AIST 1-8-31, Midorigaoka, Ikeda, Osaka 563-8577, Japan

(Received 4 June 1998; accepted 22 November 1998)

\begin{abstract}
By using a titanium dc arc of $70 \mathrm{~A}$ with a pulse modulator with specifications of $60 \mathrm{kV} / 2.5 \mathrm{~A} / 30 \mu \mathrm{s}$, titanium nitride (TiN) films were prepared on a silicon substrate $\left(n-n^{+},[111], 400 \mu \mathrm{m}\right.$ in thickness) and titanium ions were simultaneously implanted by applying voltages of $20-50 \mathrm{kV}$ of negative polarity to the substrate. The crystal orientation of the film produced by pulsed voltage application in plasma-based ion implantation (PBII) is different from that prepared by applying dc bias of $-500 \mathrm{~V}$. It is strongly (200) preferred orientation for PBII, while it is (111) and (220) preferred orientations for the dc bias. The film hardness increases with increasing pulse voltage, and the hardness for the application of $-40 \mathrm{kV}$ pulse is almost equal to that for the dc bias. Thus, the hardness maintains the same value while the crystal orientation differs from that for the dc bias.
\end{abstract} (C) 1999 American Vacuum Society. [S0734-211X(99)01702-3]

\section{INTRODUCTION}

Plasma-based ion implantation (PBII) is an attractive method for modifying the surface properties of materials in order to improve wear resistance, lifetime of work, hardness, and fatigue in engineering fields. Both metal and gas plasmas have been used for the modification. ${ }^{1-3}$ A negative high voltage applied to the substrate causes positive ions to flow toward the substrate through the sheath formed between the substrate and plasma.

To increase productivity and reduce cost, a simple ionextraction system for producing high-density ions around the substrate is desired. Our PBII facility for obtaining metal ions includes a metal plasma source in a common vacuum chamber with the substrate. As a result, PBII has the advantage that a high density of metallic ions with a large volume can be quickly implanted into the substrate.

Although the PBII technique shows some similarities to ion-assisted coating or ion beam mixing, PBII has the advantages of easy handling, large area, and low cost treatment. Pulsed ion implantation widely distributes ions inside the substrate, whereas in a conventional dc system, ions are implanted at a specified depth of the substrate. PBII also has the advantage that thin film preparation and ion implantation are simultaneously carried out and it is possible to apply to objects with three-dimensional topologies without using vacuum manipulation for obtaining uniform doses.

\footnotetext{
${ }^{a}$ Electronic mail: kyukimur@mail.doshisha.ac.jp

${ }^{b}$ Electronic mail: maruyama@cheme.kyoto-u.ac.jp

${ }^{c}$ Electronic mail: horino@onri.gp.jp
}

Titanium nitride (TiN) thin films have been prepared from nitrogen ions reacting with titanium atoms. The films were prepared both on $100 \mathrm{Cr} 6^{4}$ by a magnetron sputtering and on Ti-6Al-4V $\mathrm{V}^{5}$ using a $13.56 \mathrm{MHz}$ rf plasma.

The advantage of using metal ions instead of gas ions for preparation of $\mathrm{TiN}$ is that the implantation of $\mathrm{Ti}$ ion into the substrate can be made easily with simultaneous preparation of TiN film on the substrate. This saves production time and improves film hardness and adhesion property.

In this paper TiN thin films are prepared using a titanium dc arc in nitrogen gas. The difference of crystal orientation of TiN compared with that prepared by applying dc bias of $-500 \mathrm{~V}$ are explored as well as dynamic hardness of the film.

\section{EXPERIMENT}

A schematic diagram of the experimental facilities is shown in Fig. 1. The inner dimensions of width, depth, and height of the vacuum chamber are 400, 740, and $350 \mathrm{~mm}$, respectively. A pulsed voltage of negative polarity was supplied to a substrate via a feedthrough placed at the end of the chamber, opposite to the ion source. A water-cooled titanium cathode was mounted with a trigger electrode at the other end of the chamber. The vacuum chamber was grounded to make an anode.

Both cathode and trigger electrodes were connected to a dc power source capable of generating the maximum current of $100 \mathrm{~A}$ at output voltage of $30 \mathrm{~V}$. A trigger discharge was ignited by disconnecting the trigger electrode from the cathode to generate a dc metal arc between cathode and grounded 


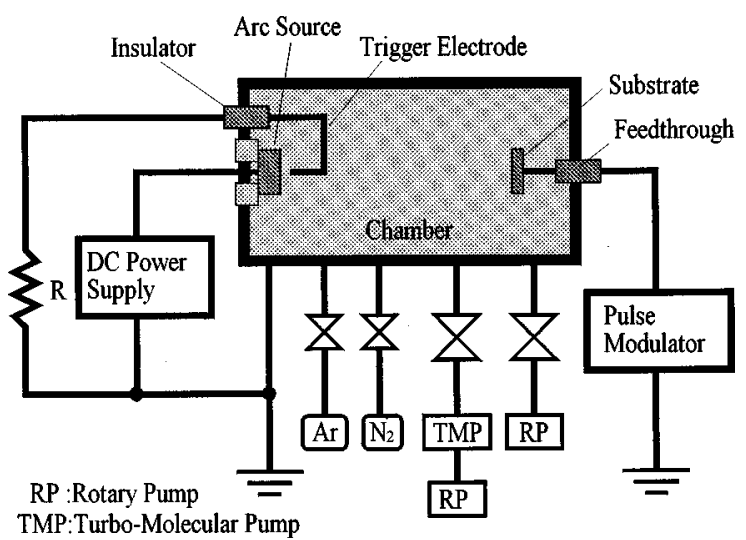

FIG. 1. A schematic diagram of the experimental facility.

chamber. Resistance $R$ in Fig. 1 suppressed the triggerdischarge current after the main arc ignition. The plasma density at the substrate was approximately $10^{10} \mathrm{~cm}^{-3}$ as measured by a Langmuir probe.

The pulse modulator was used with the following specifications: maximum output voltage of $-60 \mathrm{kV}$ and average current of 2.5 A during a pulse width of $20 \mu$ s for the maximum repetition rate of $2 \mathrm{kHz}$ corresponding to a duty cycle
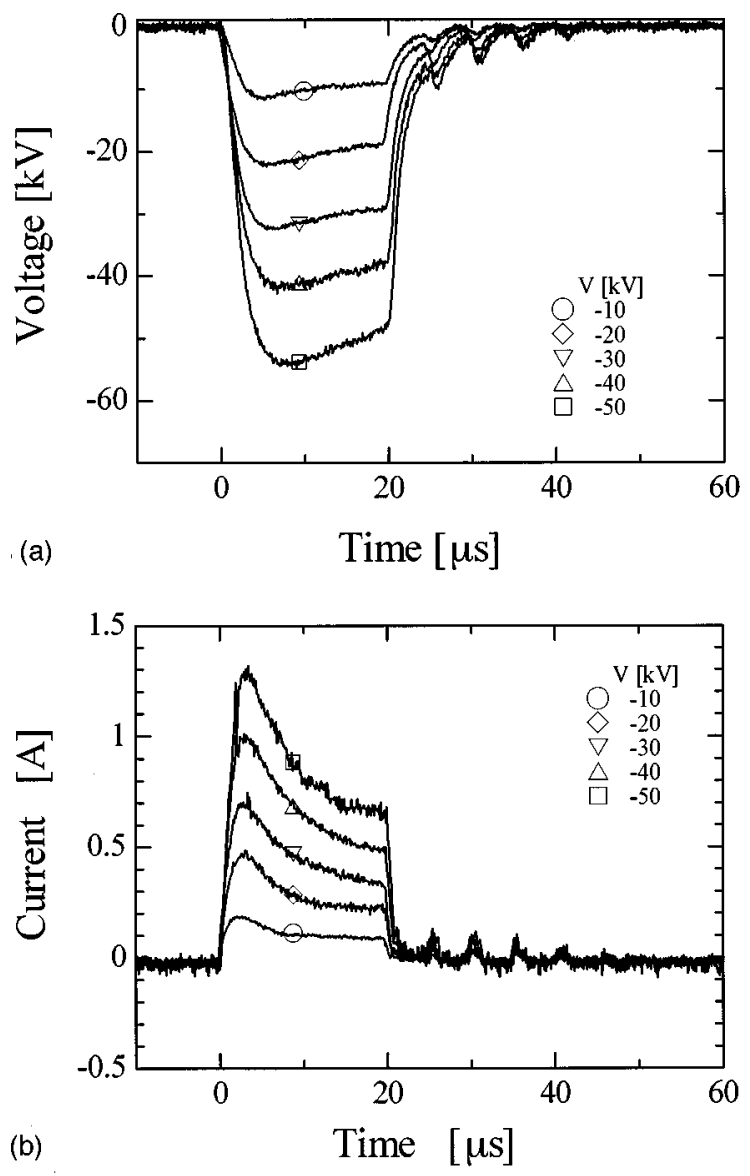

FIG. 2. Waveforms of (a) applied pulsed voltage and (b) current through the target. of about $4 \%$. As a result, the deposition occurred between pulses.

The titanium arc was generated using a dc source in nitrogen gas at pressure of about $0.27 \mathrm{~Pa}$. The typical current and voltage of the arcs were $70 \mathrm{~A}$ and $20 \mathrm{~V}$, respectively. By applying a pulsed voltage to the substrate, the titanium ions were implanted into a silicon substrate through the TiN film.

A silicon substrate $\left(n-n^{+},[111], 400 \mu \mathrm{m}\right.$ in thickness) was positioned about $400 \mathrm{~mm}$ from the ion source. The pumping system consisted of a turbomolecular pump and a rotary pump, which were positioned on the sidewall of the discharge chamber. The turbomolecular pump could be separated from the discharge chamber by a gate valve.

The voltage pulse applied to the substrate was varied from -20 to $-50 \mathrm{kV}$ at the maximum repetition rate of $1428 \mathrm{~Hz}$. The preparation time was $15 \mathrm{~min}$. The $6 \times 6 \mathrm{~mm}$ substrate was mounted on the front end of the feedthrough.

The implanted sample was characterized by x-ray photoelectron spectroscopy (XPS) and Rutherford backscattering spectrometry (RBS). For XPS the sample was etched every $2.5 \mathrm{~min}$ by argon ions to analyze the implantation profile in the silicon substrate. At argon pressure of $5.0 \times 10^{-4} \mathrm{~Pa}$, the ion-acceleration voltage was $2 \mathrm{kV}$ and the emission current was $20 \mathrm{~mA}$ in detection of the RBS signal. The incident angle of helium ions of $1.5 \mathrm{MeV}$ was $7 \mathrm{deg}$ to the normal axis of the sample surface, and a semiconductor signal detector monitored the scattering beam at an angle of $-8 \mathrm{deg}$.

\section{RESULTS AND DISCUSSION}

\section{A. Applied pulse}

Figures 2(a) and 2(b) show waveforms of the applied target voltage and current through the target. In the PBII system, the pulse is intermittently applied to the substrate in a dc metal plasma. Consequently, the deposition occurs between pulses. It should be noted that the measured current includes the secondary electron emission from the substrate.

The voltage change is approximately a rectangular form with a rise time of about $1.5 \mu$ s and a duration of about 20 $\mu \mathrm{s}$. The current exhibits a fast rise in the initial stage peaking at about $2 \mu$ s and then rapidly decreases until a normal current is achieved which continues to the end of the negative voltage pulse.

\section{B. TiN preparation}

Figure 3 shows an XPS spectrum of the Ti2 $p$ electron state for the TiN film. There are dominant peaks at $454.8 \mathrm{eV}$ $\left(2 p_{2 / 3}\right)$ and $461.0 \mathrm{eV}\left(2 p_{1 / 2}\right)$. These binding energies indicate a chemical shift of $1 \mathrm{eV}$ for the TiN combination. Shining golden TiN films were formed at nitrogen pressure of $0.27 \mathrm{~Pa}$ and at an applied voltage of $-20 \mathrm{kV}$. However, porous matt dark TiN films were obtained at nitrogen pressure of $1.1 \mathrm{~Pa}$.

Figure 4 shows TiN concentration versus etch time. It was obtained from XPS for the films at an applied voltage of -10 $\mathrm{kV}$. The film was prepared under the following conditions: arc current of dc $70 \mathrm{~A}$, preparation time of $20 \mathrm{~min}$, and 


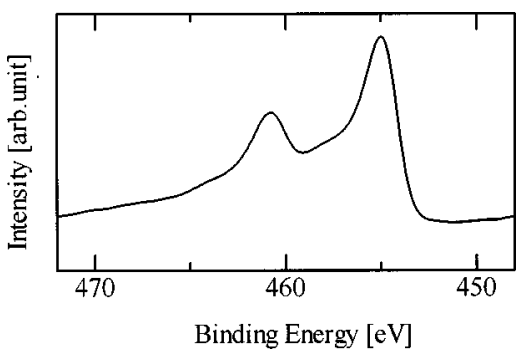

FIG. 3. XPS spectra of TiN film prepared by applied pulsed voltage of -20 $\mathrm{kV}$ and preparation time of $20 \mathrm{~min}$.

repetition rate of $600 \mathrm{~Hz}$ at nitrogen pressure of $0.27 \mathrm{~Pa}$. The etch rate was $4 \mathrm{~nm} / \mathrm{min}$, if the depth from the as-deposited surface is assumed to be proportional to the etch time. Oxygen of about $15 \%$ is recognized in the TiN film. This may be caused by the adsorption of $\mathrm{O}_{2}$ after the preparation.

The film preparation rate was obtained by dividing the film thickness by the preparation time. The rate at $0.13-0.27$ $\mathrm{Pa}$ and at $400-1400 \mathrm{~Hz}$ was about $16 \mathrm{~nm} / \mathrm{min}$, which was about $20 \%$ larger than that for the dc bias.

\section{Titanium ion implantation into silicon substrate}

Another example of the ion implantation is the titanium ion implantation into a silicon substrate in a vacuum of $10^{-3}$ $\mathrm{Pa}$ at applied voltages of -20 to $-50 \mathrm{kV}$. Figure 5 shows the Ti concentration as a function of etch time. A result for deposition is also shown in Fig. 5. Both the total dose and implantation depth increase with increasing applied voltage. Figure 6 shows XPS results for the film prepared at repetition rates from 180 to $1800 \mathrm{~Hz}$, which corresponds to a change of a duty cycle from $0.36 \%$ to $3.6 \%$.

It is seen in Figs. 5 and 6 that the titanium concentration decreases with increasing depth. Temperature rises observed commonly for the cases of varying both the applied voltage and repetition rate suggest that the mixing layer is formed by the thermal diffusion. Thus, it is highly characteristic in metallurgical implantation employing a negative high voltage that the implantation is accompanied with thermal diffusion of the deposited material into the substrate.

When the pulsed voltage of $-50 \mathrm{kV}$ is applied (Fig. 5), the temperature is inferred to become higher than it does for -20 and $-30 \mathrm{kV}$ and consequently the thermal diffusion of

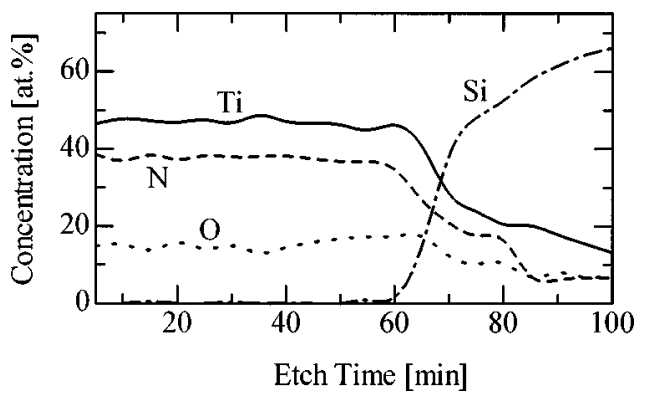

FIG. 4. XPS depth profile of TiN film on silicon substrate for substrate bias of $-10 \mathrm{kV}$

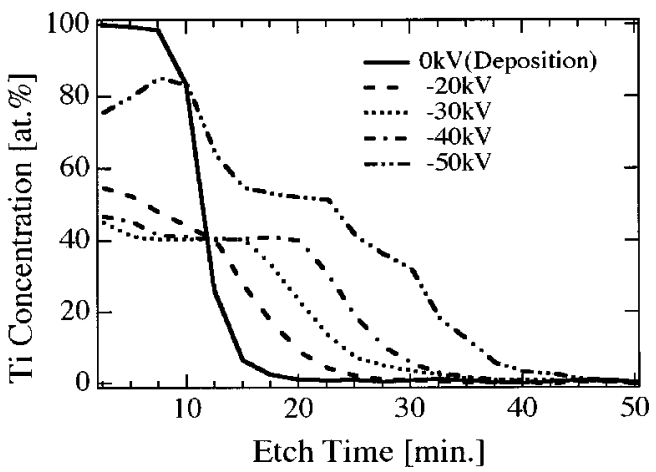

FIG. 5. Titanium concentration for the films prepared at the repetition rate of $1800 \mathrm{~Hz}$ with applied voltage of -20 to $-50 \mathrm{kV}$.

the $\mathrm{Ti}$ ions into the $\mathrm{Si}$ substrate is promoted. However, for $-50 \mathrm{kV}$ there is a noticeably higher Ti concentration in the Ti deposited layer than for the lower voltages. It is thought that the Ti implantation may saturate in the Si substrate at $-50 \mathrm{kV}$ and that further thermal diffusion of $\mathrm{Ti}$ is limited.

The dose estimated by RBS changes linearly with the applied voltage. The titanium concentrations at the surface are $40 \%-60 \%$ for the applied voltage of -20 to $-40 \mathrm{kV}$ and the concentration attains about $80 \%$ for $-50 \mathrm{kV}$. These characteristics are based on the difference of the ion energy causing a temperature rise of the substrate, because the applied voltage accelerates ions.

The titanium concentration profile in Fig. 6 also suggests the formation of a mixed layer as well as an implantation profile. For the repetition rate of $180 \mathrm{~Hz}$, the implantation effect is small. Accordingly, the profile is similar to that for deposition where the titanium concentration maintains about $100 \%$ in the deposition layer. For the repetition rate of 600 $\mathrm{Hz}$, the titanium concentration reaches only about $40 \%$ to $50 \%$ in the deposition layer. It is thought that the difference in percentage of the titanium ions between 180 and $600 \mathrm{~Hz}$ is caused by the temperature rise due to the rate of energy transfer to the sample. With increasing the repetition rate, the rate of implantation increases and causes a higher temperature rise within the near-surface region of the substrate. Accordingly, the deposited titanium would migrate into the sili-

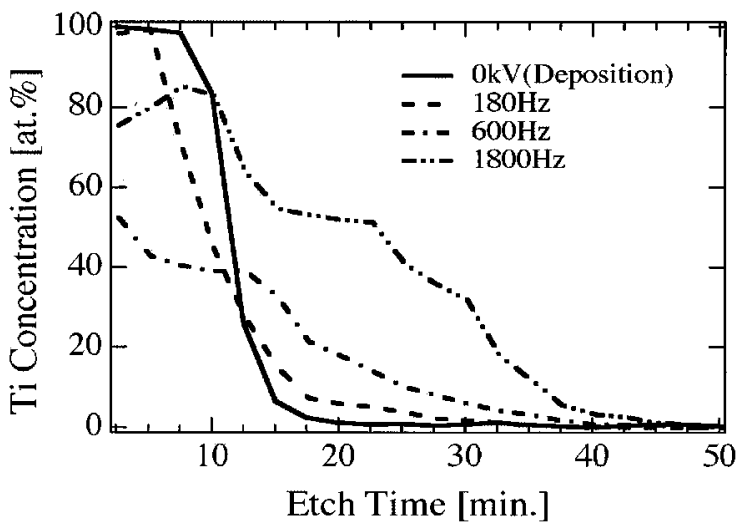

FIG. 6. Titanium concentration for the films prepared at the applied voltage of $-50 \mathrm{kV}$ with repetition rate of 180,600 , and $1800 \mathrm{~Hz}$. 
Yukimura et al.: Titanium nitride prepared by plasma-based titanium
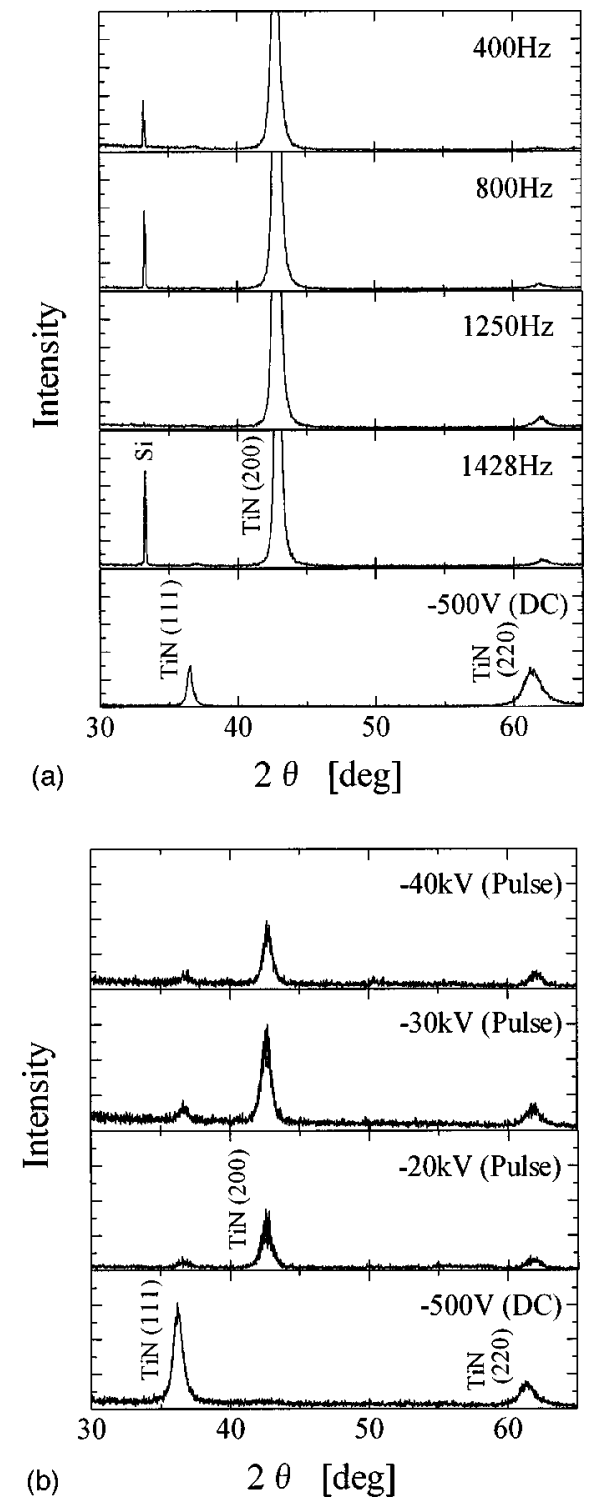

FIG. 7. XRD patterns of TiN film prepared at (a) the pulsed bias of $-20 \mathrm{kV}$ with the repetition rate of $400,800,1250$, and $1428 \mathrm{~Hz}$ and dc bias of -500 $\mathrm{V}$ and (b) the repetition rate of $400 \mathrm{~Hz}$ with the pulsed bias of $-20,-30$, and $-40 \mathrm{kV}$ and dc bias of $-500 \mathrm{~V}$.

con substrate by thermal or ion-assisted diffusion more readily at a higher repetition rate. However, it is thought that the Ti implantation may saturate in the Si substrate at 1800 $\mathrm{Hz}$ and furthermore the thermal diffusion of $\mathrm{Ti}$ is limited. This is similar to that for $50 \mathrm{kV}$ in Fig. 5 .

\section{Crystal orientation of TiN}

The crystal orientation of the TiN film was investigated for PBII in comparison to that prepared by the conventional dc bias method. The XRD patterns for the film prepared at nitrogen pressure of $0.27 \mathrm{~Pa}$ are shown in Fig. 7. It is seen that the (111) and (220) preferred orientations appear for the dc bias while strongly (200) preferred orientation appears for PBII. The (200) preferred orientation is prevailing over wide

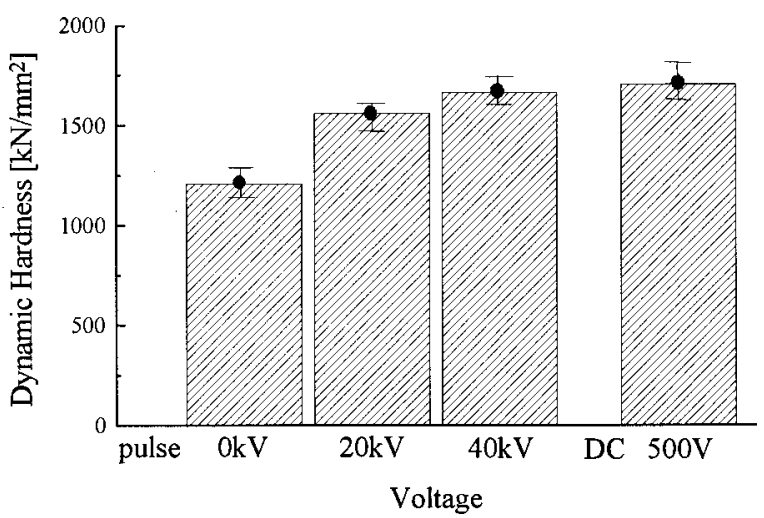

FIG. 8. Dynamic hardness of TiN film for the pulsed bias of 0 (deposition), -20 , and $-40 \mathrm{kV}$, dc bias of $-500 \mathrm{~V}$.

ranges of repetition rate (from 400 to $1428 \mathrm{~Hz}$ at $-20 \mathrm{kV}$ ) and pulsed bias voltage (from -20 to $-40 \mathrm{kV}$ at $400 \mathrm{~Hz}$ ).

There have been reports about dependences of the crystal orientation on target voltage and nitrogen concentration. In a dynamic mixing, the (111) and (200) preferred orientation appears by supplying nitrogen ions in titanium vapor ${ }^{6}$ and the density ratio of titanium to nitrogen ions was an important factor affecting the orientation. The variation of crystal orientation was also found for the TiN film prepared by the metal ion plating method: the (111) preferred orientation with dc bias from -200 to $-400 \mathrm{~V}$ and the (220) preferred orientation without dc bias. ${ }^{7}$

\section{E. Hardness of TiN}

Figure 8 shows the dynamic hardness of a TiN film for the applied voltages from -20 to $-40 \mathrm{kV}$. The result for the dc bias is also represented for comparison. The dynamic hardness was measured using a trigonal tip of the angle of $115 \mathrm{deg}$ with a load of $1 \mathrm{gf}$. The hardness increases with applied voltage and reaches about $1700 \mathrm{kN} / \mathrm{mm}^{2}$ which is almost equal to that for dc bias of $-500 \mathrm{~V}$. Thus, a similar hardness of the TiN film can be efficiently obtained even in a short application time of bias in PBII.

Figure 9 shows dependence of hardness on the depth of the film. It is seen that the hardness decreases with increasing depth. At a depth of $170 \mathrm{~nm}$, the hardness is two-thirds of that at the surface.

The results for PBII show that the crystal orientation of TiN film differs from that for the dc bias, while maintaining an approximately equal hardness of the film.

\section{CONCLUSIONS}

The TiN thin film is prepared on a silicon substrate by means of PBII using titanium plasma $(\mathrm{dc} 70 \mathrm{~A})$ in a nitrogen gas.

The crystal orientation of the TiN film produced by PBII at an applied pulse voltage of $-20 \mathrm{kV}$ to the substrate is different from that for the dc bias. The film of strongly (200) preferred orientation is prepared by PBII while the film of (111) and (220) preferred orientations are produced 


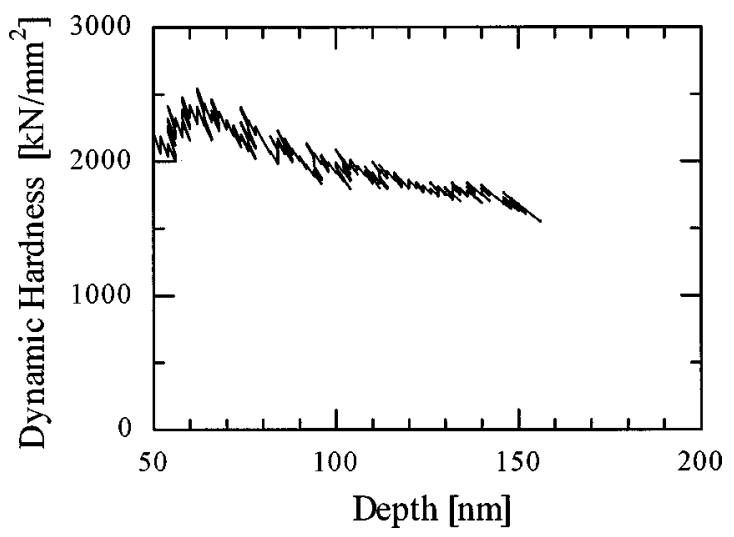

FIG. 9. Dependence of hardness of TiN film on film depth. The film was prepared at a pulsed voltage of $-20 \mathrm{kV}$ and preparation time of $30 \mathrm{~min}$.

by applying the dc bias of $-500 \mathrm{~V}$. The hardness of the TiN film increases with increasing pulse voltage and the hardness for $-40 \mathrm{kV}$ is almost equal to that for the dc bias.

Thus, the film prepared by PBII shows the same hardness but different crystal orientation compared with that for dc bias.

\section{ACKNOWLEDGMENT}

This work was supported by the Proposed Based Advanced Industrial Technology R\&D program from the New Energy and Industrial Technology Development Organization under Contract No. A-454.

${ }^{1}$ J. R. Conrad, J. L. Radtke, R. A. Dodd, F. J. Worzala, and N. C. Tran, J. Appl. Phys. 62, 4591 (1987).

${ }^{2}$ I. G. Brown, J. E. Galvin, R. A. MacGill, and R. T. Wright, Rev. Sci. Instrum. 58, 1589 (1987).

${ }^{3}$ G. A. Collins, R. Hutchings, K. T. Short, J. Tendys, and C. H. Van Der Valk, Surf. Coat. Technol. 84, 537 (1996).

${ }^{4}$ S. Schoser, J. Forget, and K. Kohlhof, Surf. Coat. Technol. 93, 339 (1997).

${ }^{5}$ S. Y. Wang, P. K. Chu, B. Y. Tang, X. C. Zeng, Y. B. Chen, and X. F. Wang, Surf. Coat. Technol. 93, 309 (1997).

${ }^{6}$ M. Kiuchi, A. Chayahara, Y. Horino, K. Fujii, and M. Satou, Appl. Surf. Sci. 60/61, 760 (1992).

${ }^{7}$ K. Okamoto and E. Kamijo, The Nissin Electric Review 32, 56 (1987) (in Japanese). 